\title{
Efficient Extraction of Bioactive Flavonoids from Ginkgo biloba Leaves Using Deep Eutectic Solvent/Water Mixture as Green Media
}

\author{
M. Yang, ${ }^{\mathrm{a}, \mathrm{b}}$ J. Cao, ${ }^{\mathrm{a}}$ F. Cao, ${ }^{\mathrm{b}}$ C. Lu, ${ }^{\mathrm{a}}$ and E. Su, ${ }^{\mathrm{a}, \mathrm{c}, *}$ \\ ${ }^{a}$ College of Light Industry and Food Engineering, Nanjing Forestry \\ University, Nanjing 210037, China \\ ${ }^{b}$ Co-innovation Center for the Sustainable Forestry in Southern China, \\ College of Forestry, Nanjing Forestry University, Nanjing 210037, China \\ 'State Key Laboratory of Natural Medicines, China Pharmaceutical \\ University, Nanjing 210009, China
}

doi: 10.15255/CABEQ.2017.1146

Original scientific paper

Received: April 18, 2017

Accepted: September 7, 2018

\begin{abstract}
Deep eutectic solvent (DES)/water mixture as alternative extraction solvent was proposed for the efficient extraction of Ginkgo flavonoids from Ginkgo biloba leaves. Fifty DESs were prepared and investigated for the extraction of Ginkgo flavonoids. Compared with the present most efficient extraction solvent (70\% ethanol in water), three DESs, choline chloride/1,3-butanediol $(\mathrm{ChCl} / \mathrm{B})$, choline chloride/levulinic acid $(\mathrm{ChCl} / \mathrm{LA} 1)$, and 1,2-propanediol/levulinic acid (P/LA1), gave obviously higher extraction yields. The extraction process was further optimized systematically. The optimized extraction conditions were as follows: $\mathrm{ChCl} / \mathrm{LA} 1$ containing $40 \%(\mathrm{w} / \mathrm{w})$ water was used as the solvent to extract Ginkgo flavonoids at a solvent to solid ratio of 10:1 (v/w) with stirring at $50{ }^{\circ} \mathrm{C}$ and $150 \mathrm{rpm}$ for $15 \mathrm{~min}$. Under the optimal conditions, 99.87 \% of Ginkgo flavonoids could be extracted from the Ginkgo biloba leaves powder at a time. Furthermore, the recovery of Ginkgo flavonoids in the DES extraction solution was efficiently achieved using macroporous resin $A B-8$, which gave a recovery yield of $93.7 \%$. The DES-based extraction combined with macroporous resin recovery developed in this work can be an efficient alternative method for the extraction and separation of Ginkgo flavonoids from Ginkgo biloba leaves.
\end{abstract}

Keywords:

deep eutectic solvents, Ginkgo biloba, Ginkgo flavonoids, extraction, recovery

\section{Introduction}

Ginkgo biloba is one of the oldest known trees on earth with fossil records dating back more than 200 million years. It survived from the era when dinosaurs became extinct. Its amazing vitality has attracted increasing exploration into its potential application in health foods and supplements ${ }^{1}$. Ginkgo biloba has been used in traditional Chinese medicine for thousands of years, and it is helpful in inhibiting the onset of dementia, slowing down cognitive decline, and reducing the incidence of cardiovascular disease because of its ability to prevent free radical damage, support microcirculation, and improve brainfunction ${ }^{2,3}$.

Ginkgo biloba leaves contain various species of active ingredients, for example ginkgolides, bilobalide, flavonoids, proanthocyanidins, alkylphenols, simple phenolic acids, and so on $^{4}$. Ginkgo flavonoids are the most important class of compounds in

"Corresponding author: Erzheng Su, Tel. +86 2585428906 ;

Fax: +86 25 85428906: E-mail address: ezhsu@njfu.edu.cn
Ginkgo biloba leaves. About 38 different flavonoids have been isolated from Ginkgo biloba leaves, and most of them are multiform glycosides of quercetin, kaempferol and isorhamnetin ${ }^{4,5}$. Ginkgo flavonoids are believed to act as protectants against capillary fragility, anti-inflammatory agents, and antioxidants, in reducing edema caused by tissue injury, and as free radical scavengers ${ }^{6}$.

Because of the potentials of the Ginkgo flavonoids as novel drugs and healthcare products, there is a high annual demand for the large-scale production of flavonoids. Preparative HPLC method has been extensively employed in the isolation of flavonoids, and many references have reported about this technology. However, it is not suitable for industrial scale preparation 7 . For many years, liquid extraction using different organic solvents has been widely adopted by most manufacturers. Ethanol, methanol and acetone are the most commonly used organic solvents $^{8}$. As is well-known, conventional organic solvents are responsible for environmental pollution because of their inflammability and volatility9. 
Ginkgo flavonoids can also be obtained using supercritical $\mathrm{CO}_{2}$ extraction technology (SFE) ${ }^{9-11}$. In contrast with conventional extraction processes using organic solvents, SFE is an ideal alternative to deal with heat-sensitive or easily oxidizable material. However, dry supercritical $\mathrm{CO}_{2}$ cannot extract flavonoids effectively, and thus addition of a cosolvent such as ethanol is needed ${ }^{8,11}$. Furthermore, the SFE is still in the laboratory-scale experimental stage.

In recent years, deep eutectic solvent (DES) has attracted increasing attention as an excellent alternative to the conventional organic solvents ${ }^{12,13}$. DESs are made up by mixing two or three components, which are capable of self-association through hydrogen bond interactions, to form eutectic mixtures having melting points lower than that of each individual component ${ }^{14}$. They are mostly formed by mixing quaternary ammonium salts with a range of hydrogen bond donors (HBDs) such as alcohols, organic acids, saccharides and amino acids ${ }^{15-17}$. Compared with conventional organic solvents, DESs possess many preferable characteristics, including safety, non-toxicity, biodegradability, sustainability, low cost, and easy preparation. Moreover, they show good physicochemical properties: adjustable viscosity, negligible volatility, wide polarity range, and high dissolving capacity for a variety of compounds ${ }^{18}$. Actually, DESs have been applied in catalysis, organic synthesis, dissolution, electrochemistry and material chemistry, aiming at increasing efficiency and reducing pollution ${ }^{15-17,19}$. There are also reports on the applications of DESs for the extraction of proteins ${ }^{20}$, phenolic compounds ${ }^{21,22}$, anthocyanin ${ }^{23}$, astaxanthin ${ }^{24}$, ginseng saponins ${ }^{25}$, catechins $^{18}$, flavonoids ${ }^{26-29}$, and many more applications are continuously being explored.

In this work, DESs were used as the alternative solvents to extract Ginkgo flavonoids from Ginkgo biloba leaves. The parameters relevant to the extraction efficiency due to the DESs conditions (hydrogen bond acceptors (HBAs), HBDs, HBA/HBD ratio, and water content) and extraction conditions (extraction method, temperature, DES to solid ratio and time) were examined systematically.

\section{Materials and methods}

\section{Materials}

The Ginkgo biloba leaves used in this study were bought from Chinese Herb Transaction Center (Bozhou, China). The leaves were dried at $65^{\circ} \mathrm{C}$ to constant weight, and then pulverized by a disintegrator. The pulverized material was sieved between 30- and 40-mesh, and then stored in a desiccator prior to use.
All compounds of analytical reagent grade used for DESs preparation were purchased from Aladdin Chemistry Co., Ltd. (Shanghai, China) and used without further purification. HPLC-grade methanol was obtained from Tedia Company, Inc., (Shanghai, China). HPLC-grade phosphoric acid was bought from J \& K Chemical Ltd. (Beijing, China). Deionized water was obtained by a Milli-Q water purification system (Millipore, Billerica, MA). The standards of quercetin, kaempferol and isorhamnetin were purchased from the National Institute of Control of Pharmaceutical and Biological Products (Beijing, China), and their purities were more than $98 \%$. All other reagents and chemicals used in the experiment were of analytical reagent grade. All samples were filtered using a filter $(0.22 \mu \mathrm{m})$ before being injected into the HPLC system.

The macroporous resins (HPD450, HPD417, DM130, ADS-17, D101 and AB-8) used to recover the target Ginkgo flavonoids from the DES extraction solution were donated by the Cangzhou Bon Adsorber Technology Co., Ltd. (Cangzhou, China), and pretreated before use according to the instructions provided by the manufacturer.

\section{DESs preparation}

DESs were prepared following the method described by Abbot et al. ${ }^{30}$ In a typical procedure, component 1 and component 2 were mixed and heated between $80{ }^{\circ} \mathrm{C}$ and $110{ }^{\circ} \mathrm{C}$ at selected molar ratios with constant stirring until homogeneous and transparent liquids were formed. If the mixture formed turbid liquid after heating for $3 \mathrm{~h}$ at $110{ }^{\circ} \mathrm{C}$, it indicated that it could not form a DES at selected ratio. The DESs prepared in this work are listed in Table 1.

\section{Extraction of flavonoids from Ginkgo biloba leaves and hydrolysis of the extract}

For the initial DES screening, an accurately weighed 50-mg sample of Ginkgo biloba leaves powder was mixed with $0.75 \mathrm{~mL}$ of extraction solvent in a $2.0-\mathrm{mL}$ microfuge tube. After brief vortexing, the mixture was extracted in the ultrasonic facilities (XO-5200DTNSN, Nanjing Sinotech Co., Ltd., China) with an ultrasound-assisted program at $100 \mathrm{~W}$ and $60{ }^{\circ} \mathrm{C}$ for $60 \mathrm{~min}$, and then centrifuged at $10,000 \mathrm{rpm}$ for $30 \mathrm{~min}^{8}$. Parent flavonoid glycosides in the supernatant were converted to their respective aglycons by acid hydrolysis, during which $300 \mu \mathrm{L}$ of the supernatant mixed with $500 \mu \mathrm{L}$ of 1.5 $\mathrm{M}$ hydrochloric acid methanol solution was heated at $90{ }^{\circ} \mathrm{C}$ for $40 \mathrm{~min}$. The hydrochloric acid concentration and time for acid hydrolysis were obtained by optimization (data not shown). The extraction yield of total flavonoids was assessed based 
on the flavonoid aglycon levels determined by HPLC analysis.

\section{DESs extraction of Ginkgo flavonoids employing different methods}

After initial DES screening, three DESs (Ch$\mathrm{Cl} / \mathrm{B}, \mathrm{ChCl} / \mathrm{LA} 1$ and $\mathrm{P} / \mathrm{LA} 1$ ) were chosen to investigate the extraction efficiency of different extraction methods. Heating, stirring, heating + stirring, and ultrasonic methods were compared for the extraction. A 50-mg sample of Ginkgo biloba leaves powder was mixed with $0.75 \mathrm{~mL}$ of the three DESs containing $30 \%(\mathrm{w} / \mathrm{w})$ of deionized water. The mixture was extracted for $10 \mathrm{~min}$ by heating at $60{ }^{\circ} \mathrm{C}$ and $0 \mathrm{rpm}$, stirring at $25^{\circ} \mathrm{C}$ and $150 \mathrm{rpm}$, heating + stirring at $60^{\circ} \mathrm{C}$ and $150 \mathrm{rpm}$, or ultrasonic treating at $50 \mathrm{~W}$ and $25^{\circ} \mathrm{C}$, respectively.

\section{Optimization of extraction conditions}

The stirring method was selected for the further optimization of extraction parameters. The parameters included water content in DES $(0,10,20,30$, $40,60,80$ and $100 \%, w / w)$, extraction temperature $\left(25,30,35,40,45,50,55\right.$ and $\left.60{ }^{\circ} \mathrm{C}\right)$, ratio between DES volume and Ginkgo biloba leaves powder weight $(7.5: 1,10: 1,12.5: 1,15: 1,20: 1,30: 1$, and $\left.50: 1, \mathrm{~mL} \mathrm{~g}^{-1}\right)$, and extraction time $(5,10,15,20,25$, 30 and $40 \mathrm{~min}$ ).

\section{Recovery of Ginkgo flavonoids from the DES extraction solution}

The recovery of the target Ginkgo flavonoids from DES extraction solution was carried out by adsorption using different macroporous resins. An amount of $5.0 \mathrm{~mL}$ of DES extraction solution was put into a $10-\mathrm{mL}$ flask, and $2.0 \mathrm{~g}$ macroporous resin was then added. The adsorption was operated at $25{ }^{\circ} \mathrm{C}$ and $150 \mathrm{rpm}$ for $6 \mathrm{~h}$. The macroporous resin was filtered out, and then desorbed with $5.0 \mathrm{~mL}$ of $95 \%(\mathrm{v} / \mathrm{v})$ ethanol solution at $25{ }^{\circ} \mathrm{C}$ and $150 \mathrm{rpm}$ for $4 \mathrm{~h}$. The Ginkgo flavonoids content in the DES extraction solution, the solution after adsorption, and the solution after desorption were determined separately. Accordingly, the adsorption yield of macroporous resin and the desorption yield of $95 \%$ $(\mathrm{v} / \mathrm{v})$ ethanol were calculated. The recovery process was performed in triplicate, and the results expressed as the mean.

\section{HPLC analysis of flavonoid aglycons}

HPLC analysis was carried out on a Waters HPLC 2695 system (Waters, USA) equipped with a Sino Chrom ODS-BPC18 column $(4.6 \times 200 \mathrm{~mm}$, $5 \mu \mathrm{m}$; Elite, China), and a $2489 \mathrm{UV}$ detector at 360 $\mathrm{nm}$. Mobile phase was a mixture of methanol and
$0.05 \%$ phosphoric acid solution $(57: 43, \mathrm{v} / \mathrm{v})$. The column temperature was maintained at $30{ }^{\circ} \mathrm{C}$, and the flow rate was set at $1.0 \mathrm{~mL} \mathrm{~min}^{-1}$ with the injection volume of $10 \mu \mathrm{L}$.

The extraction yield of total flavonoids was assessed based on the flavonol aglycon levels (as glycosides), which were calculated from the measured quantities of flavonol aglycons (quercetin, kaempferol and isorhamnetin) following acid hydrolysis ${ }^{31}$. After acid hydrolysis, the solution was diluted appropriately with the mobile phase, and filtered through a $0.22 \mu \mathrm{m}$ membrane filter before being injected into the HPLC system. The factors for conversion from aglycon mass to glycoside mass are 2.51 for quercetin, 2.64 for kaempferol, and 2.39 for isorhamnetin. In that case, the mass of flavonoids extracted from Ginkgo biloba leaves $\left(m_{\text {flavonoids }}\right)$ was calculated by $m_{\text {flavonoids }}=2.51 \cdot m_{\text {quercetin }}$ $+2.64 \cdot m_{\text {kaempferol }}+2.39 \cdot m_{\text {isorhamnetin }}$. The extraction yield of total flavonoids obtained was expressed asextraction yield $\left(\mathrm{mg} \mathrm{g}^{-1}\right)=m_{\text {flavonoids }} / m_{\text {leaf }}$, where $m_{\text {leaf }}$ was the mass of Ginkgo biloba leaves powder.

Calibration curves were established for the three flavonoid aglycons by plotting the concentrations of standard solutions versus peak areas. The retention times of quercetin, kaempferol, and isorhamnetin were $7.861,12.306$, and $13.642 \mathrm{~min}$, respectively. Linear regression equations were $y=33491 x-22319\left(R^{2}=0.9997\right)$ for quercetin, $y=37562 x+25123\left(R^{2}=0.9956\right)$ for kaempferol, and $y=35235 x+5489$. $7\left(R^{2}=0.9997\right)$ for isorhamnetin. The linear ranges were $0-200 \mu \mathrm{g} \mathrm{mL}$ for quercetin and kaempferol, and $0-50 \mu \mathrm{g} \mathrm{mL}^{-1}$ for isorhamnetin.

\section{Results and discussion}

\section{Preparation of various types of DESs}

DES scan be prepared from combinations of two components at various molar ratios using heating, evaporating, or freeze-drying method ${ }^{25}$. In this work, the heating method was used because its procedure is simple. The main criteria for DES component selection in the present work were low cost, safety, and good biodegradability. Based on previous reports and our own experience ${ }^{15-17,32}$, a number of components were used with the aim of forming DESs at various ratios. Choline chloride, as the most used HBA, was firstly chosen to form DESs with different alcohols, sugars, organic acids, and urea. Fifteen combinations were initially tested. As shown in Table 1 (Entries 1-15), 10 combinations were found to be stable as clear liquids, 4 combinations were found to be viscous liquids, and $1 \mathrm{com}$ bination formed a transparent gel. Further, betaine and proline were used to replace the choline chlo- 
Table 1 -DESs prepared for extracting Ginkgo flavonoids

\begin{tabular}{|c|c|c|c|c|c|}
\hline Entry & Abbreviation & Component 1 & Component 2 & Molar ratio & Appearance \\
\hline 1 & $\mathrm{ChCl} / \mathrm{G}$ & Choline chloride & Glycerol & $1: 2$ & Clear liquid \\
\hline 2 & $\mathrm{ChCl} / \mathrm{EG}$ & Choline chloride & Ethylene glycol & $1: 2$ & Clear liquid \\
\hline 3 & $\mathrm{ChCl} / \mathrm{P}$ & Choline chloride & 1,2-Propanediol & $1: 2$ & Clear liquid \\
\hline 4 & $\mathrm{ChCl} / \mathrm{B}$ & Choline chloride & 1,3-Butanediol & $1: 3$ & Clear liquid \\
\hline 5 & $\mathrm{ChCl} / \mathrm{DS}$ & Choline chloride & D-Sorbitol & $1: 1$ & Viscous and clear liquid \\
\hline 6 & $\mathrm{ChCl} / \mathrm{DG}$ & Choline chloride & D-Glucose & $1: 1$ & Transparent gel \\
\hline 7 & $\mathrm{ChCl} / \mathrm{GA} 1$ & Choline chloride & Glutaric acid & $1: 1$ & Clear liquid \\
\hline 8 & $\mathrm{ChCl} / \mathrm{GA} 2$ & Choline chloride & Glycolic acid & $1: 1$ & Clear liquid \\
\hline 9 & $\mathrm{ChCl} / \mathrm{MA} 1$ & Choline chloride & Malonic acid & $1: 1$ & Clear liquid \\
\hline 10 & $\mathrm{ChCl} / \mathrm{MA} 2$ & Choline chloride & Malic acid & $1: 1$ & Viscous and clear liquid \\
\hline 11 & $\mathrm{ChCl} / \mathrm{LA} 1$ & Choline chloride & Levulinic acid & $1: 2$ & Clear liquid \\
\hline 12 & $\mathrm{ChCl} / \mathrm{LA} 2$ & Choline chloride & Lactic acid & $1: 1$ & Clear liquid \\
\hline 13 & $\mathrm{ChCl} / \mathrm{CA}$ & Choline chloride & Citric acid & $1: 1$ & Viscous and clear liquid \\
\hline 14 & $\mathrm{ChCl} / \mathrm{TA}$ & Choline chloride & L-(+)-Tartaric acid & $2: 1$ & Viscous and clear liquid \\
\hline 15 & $\mathrm{ChCl} / \mathrm{U}$ & Choline chloride & Urea & $1: 2$ & Clear liquid \\
\hline 16 & $\mathrm{BE} / \mathrm{G}$ & Betaine & Glycerol & $1: 2$ & Clear liquid \\
\hline 17 & $\mathrm{BE} / \mathrm{EG}$ & Betaine & Ethylene glycol & $1: 3$ & Clear liquid \\
\hline 18 & $\mathrm{BE} / \mathrm{P}$ & Betaine & 1,2-Propanediol & $1: 3$ & Clear liquid \\
\hline 19 & $\mathrm{BE} / \mathrm{B}$ & Betaine & 1,3-Butanediol & $1: 3$ & Clear liquid \\
\hline 20 & $\mathrm{BE} / \mathrm{X}$ & Betaine & Xylitol & $1: 2$ & Viscous and clear liquid \\
\hline 21 & $\mathrm{BE} / \mathrm{DS}$ & Betaine & D-Sorbitol & $1: 2$ & Viscous and clear liquid \\
\hline 22 & $\mathrm{BE} / \mathrm{GA} 2$ & Betaine & Glycolic acid & $1: 1$ & Clear liquid \\
\hline 23 & $\mathrm{BE} / \mathrm{MA} 1$ & Betaine & Malonic acid & $1: 2$ & Viscous and clear liquid \\
\hline 24 & $\mathrm{BE} / \mathrm{OA}$ & Betaine & Oxalic acid & $1: 1$ & Clear liquid \\
\hline 25 & $\mathrm{BE} / \mathrm{MA} 2$ & Betaine & Malic acid & $1: 1$ & Viscous and clear liquid \\
\hline 26 & $\mathrm{BE} / \mathrm{LA} 1$ & Betaine & Levulinic acid & $1: 2$ & Clear liquid \\
\hline 27 & $\mathrm{BE} / \mathrm{LA} 2$ & Betaine & Lactic acid & $1: 1$ & Clear liquid \\
\hline 28 & $\mathrm{BE} / \mathrm{CA}$ & Betaine & Citric acid & $1: 1$ & Viscous and clear liquid \\
\hline 29 & $\mathrm{BE} / \mathrm{TA}$ & Betaine & L-(+)-Tartaric acid & $2: 1$ & Unable to form clear liquid \\
\hline 30 & $\mathrm{PR} / \mathrm{G}$ & Proline & Glycerol & $1: 1$ & Unable to form clear liquid \\
\hline 31 & $\mathrm{PR} / \mathrm{P}$ & Proline & 1,2-Propanediol & $1: 1$ & Unable to form clear liquid \\
\hline 32 & $\mathrm{PR} / \mathrm{B}$ & Proline & 1,3-Butanediol & $1: 1$ & Unable to form clear liquid \\
\hline 33 & $\mathrm{PR} / \mathrm{X}$ & Proline & Xylitol & $1: 1$ & Unable to form clear liquid \\
\hline 34 & PR/DS & Proline & D-Sorbitol & $1: 1$ & Unable to form clear liquid \\
\hline 35 & PR/MA2 & Proline & Malic acid & $1: 1$ & Viscous and clear liquid \\
\hline 36 & PR/GA1 & Proline & Glutaric acid & $1: 1$ & Unable to form clear liquid \\
\hline 37 & $\mathrm{PR} / \mathrm{GA} 2$ & Proline & Glycolic acid & $1: 1$ & Clear liquid \\
\hline 38 & PR/LA1 & Proline & Levulinic acid & $1: 1$ & Unable to form clear liquid \\
\hline 39 & $\mathrm{PR} / \mathrm{LA} 2$ & Proline & Lactic acid & $1: 1$ & Clear liquid \\
\hline 40 & $\mathrm{PR} / \mathrm{CA}$ & Proline & Citric acid & $1: 1$ & Viscous and clear liquid \\
\hline 41 & $\mathrm{~B} / \mathrm{LA} 2$ & 1,3-Butanediol & Lactic acid & $1: 1$ & Clear liquid \\
\hline 42 & $\mathrm{~B} / \mathrm{LA} 1$ & 1,3-Butanediol & Levulinic acid & $1: 1$ & Clear liquid \\
\hline 43 & $\mathrm{~B} / \mathrm{MA} 2$ & 1,3-Butanediol & Malic acid & $1: 1$ & Clear liquid \\
\hline 44 & $\mathrm{~B} / \mathrm{CA}$ & 1,3-Butanediol & Citric acid & $1: 1$ & Clear liquid \\
\hline 45 & $\mathrm{~B} / \mathrm{GA} 2$ & 1,3-Butanediol & Glycolic acid & $1: 1$ & Clear liquid \\
\hline 46 & $\mathrm{~B} / \mathrm{GA} 1$ & 1,3-Butanediol & Glutaric acid & $2: 1$ & Clear liquid \\
\hline 47 & P/LA2 & 1,2-Propanediol & Lactic acid & $1: 1$ & Clear liquid \\
\hline 48 & $\mathrm{P} / \mathrm{LA} 1$ & 1,2-Propanediol & Levulinic acid & $1: 1$ & Clear liquid \\
\hline 49 & $\mathrm{P} / \mathrm{MA} 2$ & 1,2-Propanediol & Malic acid & $1: 1$ & Clear liquid \\
\hline 50 & $\mathrm{P} / \mathrm{CA}$ & 1,2-Propanediol & Citric acid & $1: 1$ & Clear liquid \\
\hline 51 & P/GA2 & 1,2-Propanediol & Glycolic acid & $1: 1$ & Clear liquid \\
\hline 52 & P/GA1 & 1,2-Propanediol & Glutaric acid & $2: 1$ & Clear liquid \\
\hline 53 & $\mathrm{X} / \mathrm{LA} 2$ & Xylitol & Lactic acid & $1: 1$ & Clear liquid \\
\hline 54 & $\mathrm{X} / \mathrm{LA} 1$ & Xylitol & Levulinic acid & $1: 1$ & Clear liquid \\
\hline 55 & $\mathrm{X} / \mathrm{MA} 2$ & Xylitol & Malic acid & $1: 1$ & Clear liquid \\
\hline 56 & $\mathrm{X} / \mathrm{CA}$ & Xylitol & Citric acid & $1: 1$ & Clear liquid \\
\hline 57 & $\mathrm{X} / \mathrm{GA} 2$ & Xylitol & Glycolic acid & $1: 1$ & Clear liquid \\
\hline 58 & $\mathrm{X} / \mathrm{GA} 1$ & Xylitol & Glutaric acid & $2: 1$ & Clear liquid \\
\hline
\end{tabular}


Table 2 -Amount of flavonoids extracted from Ginkgo biloba leaves using different DESs and reference solvents ${ }^{a}$

\begin{tabular}{|c|c|c|c|c|c|}
\hline Entry & Solvents & $\begin{array}{l}\text { Extraction yield } \\
\qquad\left(\mathrm{mg} \mathrm{g}^{-1}\right)\end{array}$ & Entry & Solvents & $\begin{array}{l}\text { Extraction yield } \\
\qquad\left(\mathrm{mg} \mathrm{g}^{-1}\right)\end{array}$ \\
\hline 1 & $\mathrm{ChCl} / \mathrm{G}$ & $9.05 \pm 0.31$ & 30 & PR/MA2 & $8.76 \pm 0.24$ \\
\hline 2 & $\mathrm{ChCl} / \mathrm{EG}$ & $9.61 \pm 0.23$ & 31 & $\mathrm{PR} / \mathrm{CA}$ & $8.69 \pm 0.35$ \\
\hline 3 & $\mathrm{ChCl} / \mathrm{P}$ & $9.77 \pm 0.08$ & 32 & $\mathrm{PR} / \mathrm{GA} 2$ & $8.21 \pm 0.24$ \\
\hline 4 & $\mathrm{ChCl} / \mathrm{B}$ & $10.27 \pm 0.11$ & 33 & B/LA2 & $8.73 \pm 0.16$ \\
\hline 5 & $\mathrm{ChCl} / \mathrm{DS}$ & $9.17 \pm 0.15$ & 34 & B/LA1 & $10.08 \pm 0.09$ \\
\hline 6 & $\mathrm{ChCl} / \mathrm{DG}$ & $7.77 \pm 0.07$ & 35 & B/MA2 & $10.04 \pm 0.13$ \\
\hline 7 & $\mathrm{ChCl} / \mathrm{GA} 1$ & $9.89 \pm 0.23$ & 36 & $\mathrm{~B} / \mathrm{CA}$ & $8.47 \pm 0.24$ \\
\hline 8 & $\mathrm{ChCl} / \mathrm{GA} 2$ & $9.60 \pm 0.28$ & 37 & B/GA2 & $10.04 \pm 0.27$ \\
\hline 9 & $\mathrm{ChCl} / \mathrm{MA} 1$ & $9.58 \pm 0.16$ & 38 & B/GA1 & $9.55 \pm 0.27$ \\
\hline 10 & $\mathrm{ChCl} / \mathrm{MA} 2$ & $9.46 \pm 0.29$ & 39 & $\mathrm{P} / \mathrm{LA} 2$ & $10.12 \pm 0.32$ \\
\hline 11 & $\mathrm{ChCl} / \mathrm{LA} 1$ & $10.32 \pm 0.14$ & 40 & P/LA1 & $10.30 \pm 0.35$ \\
\hline 12 & $\mathrm{ChCl} / \mathrm{LA} 2$ & $9.63 \pm 0.17$ & 41 & $\mathrm{P} / \mathrm{MA} 2$ & $6.17 \pm 0.10$ \\
\hline 13 & $\mathrm{ChCl} / \mathrm{CA}$ & $8.67 \pm 0.11$ & 42 & $\mathrm{P} / \mathrm{CA}$ & $7.57 \pm 0.25$ \\
\hline 14 & $\mathrm{ChCl} / \mathrm{TA}$ & $8.67 \pm 0.09$ & 43 & $\mathrm{P} / \mathrm{GA} 2$ & $10.14 \pm 0.19$ \\
\hline 15 & $\mathrm{ChCl} / \mathrm{U}$ & $7.74 \pm 0.12$ & 44 & P/GA1 & $10.16 \pm 0.18$ \\
\hline 16 & $\mathrm{BE} / \mathrm{G}$ & $9.14 \pm 0.22$ & 45 & $\mathrm{X} / \mathrm{LA} 2$ & $6.28 \pm 0.09$ \\
\hline 17 & $\mathrm{BE} / \mathrm{EG}$ & $9.51 \pm 0.18$ & 46 & X/LA1 & $8.61 \pm 0.25$ \\
\hline 18 & $\mathrm{BE} / \mathrm{P}$ & $8.40 \pm 0.26$ & 47 & $\mathrm{X} / \mathrm{MA} 2$ & $7.30 \pm 0.12$ \\
\hline 19 & $\mathrm{BE} / \mathrm{B}$ & $10.04 \pm 0.34$ & 48 & $\mathrm{X} / \mathrm{CA}$ & $7.75 \pm 0.05$ \\
\hline 20 & $\mathrm{BE} / \mathrm{X}$ & $8.52 \pm 0.15$ & 49 & $\mathrm{X} / \mathrm{GA} 2$ & $7.44 \pm 0.09$ \\
\hline 21 & $\mathrm{BE} / \mathrm{DS}$ & $7.76 \pm 0.10$ & 50 & X/GA1 & $8.93 \pm 0.32$ \\
\hline 22 & $\mathrm{BE} / \mathrm{GA} 2$ & $8.28 \pm 0.25$ & 51 & Water & $7.47 \pm 0.29$ \\
\hline 23 & $\mathrm{BE} / \mathrm{MA} 1$ & $9.84 \pm 0.31$ & 52 & Ethanol & $9.87 \pm 0.19$ \\
\hline 24 & $\mathrm{BE} / \mathrm{OA}$ & $8.36 \pm 0.22$ & 53 & 1,3-Butanediol & $8.28 \pm 0.13$ \\
\hline 25 & BE/MA2 & $8.64 \pm 0.20$ & 54 & 1,2-Propanediol & $8.24 \pm 0.24$ \\
\hline 26 & BE/LA1 & $9.86 \pm 0.38$ & 55 & Levulinic acid & $9.40 \pm 0.22$ \\
\hline 27 & $\mathrm{BE} / \mathrm{LA} 2$ & $8.72 \pm 0.27$ & 56 & Lactic acid & $8.20 \pm 0.19$ \\
\hline 28 & $\mathrm{BE} / \mathrm{CA}$ & $8.61 \pm 0.12$ & 57 & Choline chloride & $8.40 \pm 0.21$ \\
\hline 29 & $\mathrm{PR} / \mathrm{LA} 2$ & $8.26 \pm 0.33$ & & & \\
\hline
\end{tabular}

${ }^{\mathrm{a}}$ Extraction conditions: $70 \%(\mathrm{w} / \mathrm{w})$ aqueous solution was used as solvent to extract Ginkgo flavonoids at $100 \mathrm{~W}$ and $60{ }^{\circ} \mathrm{C}$ for $60 \mathrm{~min}$ with a solid to solvent ratio of $1: 15$.

ride to form DESs with different alcohols and organic acids. Twenty-five combinations were investigated (Entries 16-40 in Table 1). Ten of them formed a stable clear liquid, 7 formed viscous liquids, and 8 could not form clear liquid. Lastly, some alcohols and organic acids that could easily form DESs with choline chloride or betaine were selected to form another 18 DESs (Entries 41-58 in Table 1 ), and all of them were found to be stable clear liquids. As a result, 50 different types of DESs were successfully produced (Entries 1-28, 35, 37, 39 and 40-58 in Table 1). After preparation, the DESs were dehydrated by incubating with $3 \AA$ molecular sieves for several days before extraction experiments.

\section{Selection of DESs}

The produced 50 DESs were used as solvents to extract flavonoids from Ginkgo biloba leaves. At present, $70 \%$ ethanol in water is the most efficient solvent for Ginkgo flavonoids extraction ${ }^{8}$. It has also been reported that the viscosity of DESs is gen- erally high, which hinders the mass transfer of compounds from plant matrix to extraction solvent ${ }^{18}$. Therefore, in order to compare the extraction effect with $70 \%$ ethanol and reduce the viscosity of DESs, all produced DESs were mixed with deionized water at 7:3 (w/w) and used for the screening. The results are shown in Table 2. It could be found that all of the DESs could extract the Ginkgo flavonoids with varied extraction yields. Eighteen DESs (Entries $2,3,7,8,9,10,12,17,19,23,26,34,35,37$, $38,39,43$ and 44 in Table 2) exhibited comparable extraction yields to the most efficient reference solvent, $70 \%$ ethanol $(p>0.05)$. Three DESs (Entries 4,11 , and 40 in Table 2) gave obviously higher extraction yields than $70 \%$ ethanol $(p<0.05)$. The extraction yields of $\mathrm{ChCl} / \mathrm{B}, \mathrm{ChCl} / \mathrm{LA} 1$ and $\mathrm{P} / \mathrm{LA} 1$ (Entries 4, 11 and 40 in Table 2) attained to 10.27, 10.32 and $10.30 \mathrm{mg} \mathrm{g}^{-1}$, respectively, which were also the highest among the 50 DESs. One of the possible explanations for the high extraction yields of these three DESs may be the good liquidity, 
Table 3 -Amount of flavonoids extracted from Ginkgo biloba leaves using different extraction methods ${ }^{a}$

\begin{tabular}{c|c|c|c|c}
\hline \multirow{2}{*}{ DESs } & \multicolumn{4}{|c}{ Extraction yield $\left(\mathrm{mg} \mathrm{g}^{-1}\right)$} \\
\cline { 2 - 5 } & Heating & $\begin{array}{c}\text { Heating }+ \\
\text { Stirring }\end{array}$ & Stirring & Ultrasound \\
\hline $\mathrm{ChCl} / \mathrm{B}$ & $4.44 \pm 0.21$ & $10.01 \pm 0.19$ & $5.66 \pm 0.17$ & $4.34 \pm 0.18$ \\
$\mathrm{ChCl} / \mathrm{LA} 1$ & $5.41 \pm 0.08$ & $10.27 \pm 0.16$ & $6.61 \pm 0.16$ & $6.22 \pm 0.04$ \\
$\mathrm{P} / \mathrm{LA} 1$ & $5.55 \pm 0.05$ & $10.24 \pm 0.16$ & $6.47 \pm 0.19$ & $6.09 \pm 0.04$ \\
\hline
\end{tabular}

${ }^{a}$ Extraction conditions: $70 \%(\mathrm{w} / \mathrm{w})$ DES aqueous solution was used as solvent to extract Ginkgo flavonoids at a solid to solvent ratio of $1: 15$ with heating method (at $60^{\circ} \mathrm{C}$ and $0 \mathrm{rpm}$ ), stirring method (at $25{ }^{\circ} \mathrm{C}$ and $150 \mathrm{rpm}$ ), heating + stirring method (at $60{ }^{\circ} \mathrm{C}$ and $150 \mathrm{rpm}$ ), and ultrasonic method (at $50 \mathrm{~W}$ and $25^{\circ} \mathrm{C}$ ).

which was contributed by the liquid form of one or two constituents of DESs. The constituents of Ch$\mathrm{Cl} / \mathrm{B}, \mathrm{ChCl} / \mathrm{LA} 1$ and $\mathrm{P} / \mathrm{LA} 1$ (choline chloride, 1,3-butanediol, 1,2-propanediol or levulinic acid) were used to prepare $70 \%$ aqueous solutions, and employed as solvents to extract the Ginkgo flavonoids. It could be found that all the constituent 70 $\%$ aqueous solutions gave lower extraction yields than the corresponding three constituent DES solutions (Entries 53-55, 57 in Table 2). These results showed that high extraction yields of $\mathrm{ChCl} / \mathrm{B}, \mathrm{ChCl} /$ LA1 and P/LA1 originated from DES formation. Compared with water as solvent, most of the DES solutions exhibited higher extraction yield (Entry 51, Table 2). $\mathrm{ChCl} / \mathrm{DG}, \mathrm{BE} / \mathrm{DS}, \mathrm{P} / \mathrm{MA} 2$, and $\mathrm{P} / \mathrm{CA}$ (Entries 6, 21, 41, 42 in Table 2) showed lower extraction yields, which may have resulted from their high viscosity. Besides viscosity, the extraction yield was also affected by other properties of DES, which could be adjusted by the nature of constituent. Fixing one component of DES, the extraction yield of a different DES was attempted to be correlated with the choice of another component, but the correlation failed. As for the DESs, their properties are complicated because DESs are in fact binary mixtures, in contrast to the protic organic solvents which are pure substances. This highlights the difficulty in predicting the extraction yield of a DES. Finally, $\mathrm{ChCl} / \mathrm{B}, \mathrm{ChCl} / \mathrm{LA} 1$ and $\mathrm{P} / \mathrm{LA} 1$ were selected for further investigation.

\section{Comparison of different extraction methods}

Ultrasound-assisted extraction (UAE) was employed as the extraction method in the initial screening of DESs due to its simplicity for comparing multiple samples at the same time. Based on previous reports involving DES-based extraction ${ }^{25,28}$, three other commonly used extraction methods, stirring, heating, and heating+stirring, were compared with UAE method with $\mathrm{ChCl} / \mathrm{B}, \mathrm{ChCl} / \mathrm{LA} 1$ and $\mathrm{P} /$ LA1 being used as the extraction solvents (Table 3).
At $25{ }^{\circ} \mathrm{C}$, the stirring and ultrasonic method exhibited no obvious differences inextraction yields for the three DESs. At $60{ }^{\circ} \mathrm{C}$, however, heating and heating + stirring method showed significant differences in extraction yields for the three DESs. The extraction yield of heating + stirring method was almost two times higher than those of heating method for the three DESs. While stirring at $150 \mathrm{rpm}$, the temperature increased from $25{ }^{\circ} \mathrm{C}$ to $60{ }^{\circ} \mathrm{C}$, which enhanced the extraction yields for the three DESs by about $40 \%$. Stirring or heating alone was inefficient, and combination of heating and stirring should be a good choice. As far as the three DESs are concerned, the extraction yield of $\mathrm{ChCl} / \mathrm{B}$ was always lower than that of $\mathrm{ChCl} / \mathrm{LA} 1$ and $\mathrm{P} / \mathrm{LA} 1$. Accordingly, extraction conditions were further optimized based on stirring method at $25{ }^{\circ} \mathrm{C}$ using $\mathrm{ChCl} / \mathrm{LA} 1$ and P/LA1 as the extraction solvents.

\section{Optimization of the extraction conditions}

\section{Effect of water content in DES}

The addition of water to DES can cause a decrease in DES viscosity, which is beneficial to the mass transport from plant matrices to solution. Also, addition of water to DES can modulate the polarity of the DES, which may preferably match the polarity of the target compounds and give better extraction yield. In order to determine the optimum water content in DES for Ginkgo flavonoids extraction, the extraction procedures were performed in $\mathrm{ChCl} / \mathrm{LA} 1$ and $\mathrm{P} / \mathrm{LA} 1$ with different water content $(0-100 \%, w / w)$. The results are shown in Fig. 1. It could be observed that the extraction yields reached maximum when the water content was 40 $60 \%(\mathrm{w} / \mathrm{w})$ for both of the DESs. When the water content increased from 0 to $40 \%(\mathrm{w} / \mathrm{w})$, the extraction yields increased obviously. However, high-

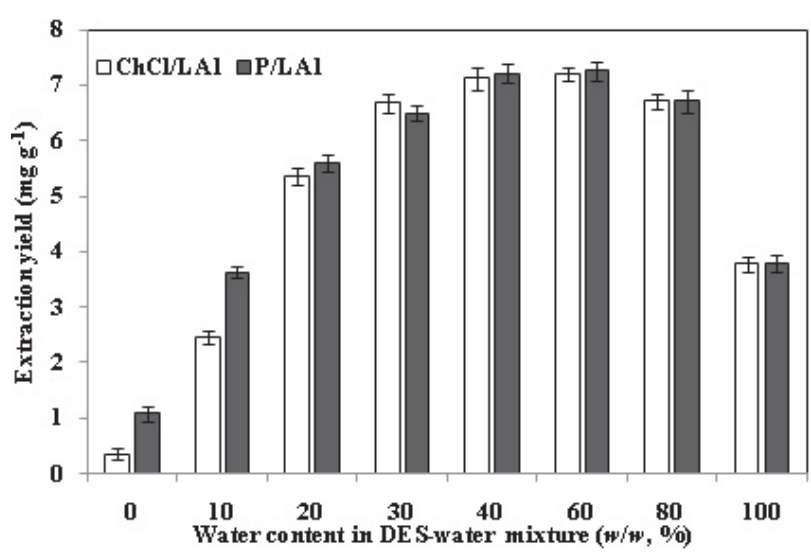

Fig. 1 - Effect of the water content in DES-water mixture on the extraction yield of Ginkgo flavonoids. Varied DES aqueous solution was used as extraction solvent at a solvent to solid ratio of $15: 1$ with stirring at $25^{\circ} \mathrm{C}$ and $150 \mathrm{rpm}$ for $10 \mathrm{~min}$. 


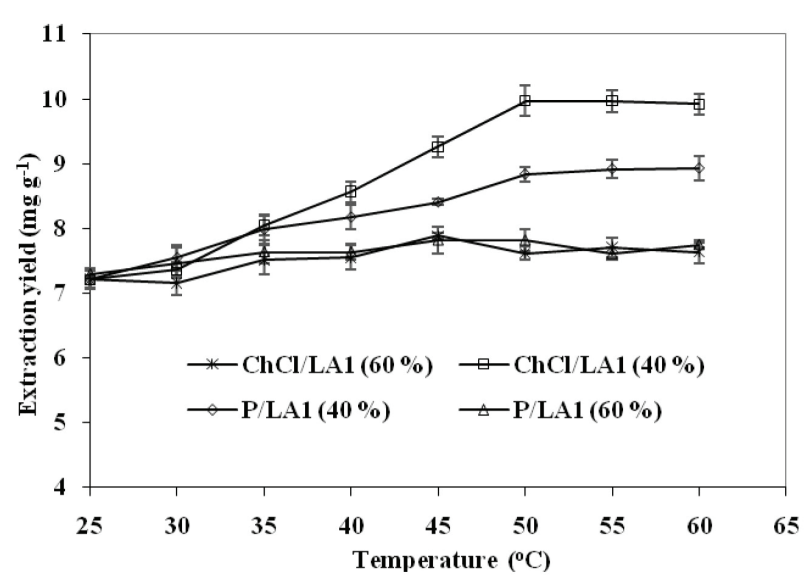

Fig. 2 - Effect of temperature on the extraction yield of Ginkgo flavonoids. ChCl/LAl and P/LAl containing $40 \%$ or $60 \%(w / w)$ water were used as extraction solvents at a solvent to solid ratio of 15:1 with stirring at varied temperatures and $150 \mathrm{rpm}$ for $10 \mathrm{~min}$.

er concentration of water in $\mathrm{ChCl} / \mathrm{LA} 1$ and $\mathrm{P} / \mathrm{LA} 1$ (e.g. $80 \%, w / w)$ led to the decrease in the amount of target flavonoids extracted. The addition of water could effectively reduce the viscosity, and could favorably affect the solvent polarity, while excessive water content would probably decrease the interactions between DES and flavonoids, and further increase unfavorably the polarity of the solvent mixture. The concentrations of $40 \%$ and $60 \%(\mathrm{w} / \mathrm{w})$ water in $\mathrm{ChCl} / \mathrm{LA} 1$ and $\mathrm{P} / \mathrm{LA} 1$ were selected for subsequent experiments.

\section{Effect of extraction temperature}

Extraction temperature is a crucial factor benefitting the increase of extraction yield according to the results of the comparison of different extraction methods. The Ginkgo flavonoid glycosides are adsorbed on the plant matrix by physical adsorption and/or chemical interactions. Raising temperature is one of the most convenient measures for decreasing the adsorption and/or interactions for desorption and dissolution of the flavonoids compounds to the extraction solvent. Also, the DES viscosity will decrease and its diffusivity will increase at higher temperature, which will improve the release of Ginkgo flavonoid compounds from plant matrix to the DES. The effect of temperature on the extraction yield of Ginkgo flavonoids was investigated at the temperatures of $25,30,35,40,45,50,55$ and $60^{\circ} \mathrm{C}$, respectively. The results are shown in Fig. 2. It could befound that the extraction yields increased by raising temperature from $25^{\circ} \mathrm{C}$, and reached maximum at about $50{ }^{\circ} \mathrm{C}$ for both $\mathrm{ChCl} / \mathrm{LA} 1$ and $\mathrm{P} /$ LA1 containing $40 \%(\mathrm{w} / \mathrm{w})$ water. This result could be explained by the increase in mass transport and decrease in viscosity with the increase in temperature as mentioned above. However, as for $\mathrm{ChCl} /$ LA1 and P/LA1 containing $60 \%(\mathrm{w} / \mathrm{w})$ water, the

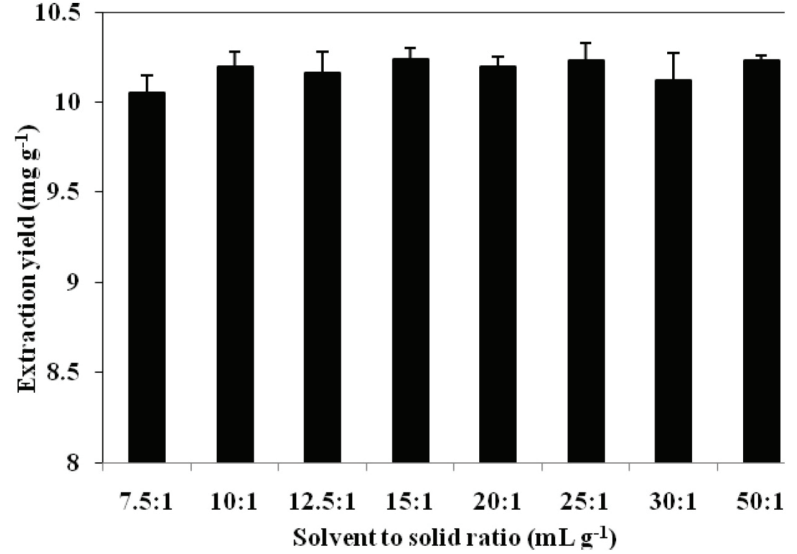

Fig. 3 - Effect of solvent to solid ratio on the extraction yield of Ginkgo flavonoids. ChCl/LAl containing $40 \%(w / w)$ water was used as extraction solvent at different solvent to solid ratios with stirring at $50{ }^{\circ} \mathrm{C}$ and $150 \mathrm{rpm}$ for $10 \mathrm{~min}$.

temperature increase could not improve the extraction yields remarkably. Addition of $60 \%(\mathrm{w} / \mathrm{w})$ water might adversely affect the hydrogen bonding between the two components of DES, and influence the van der Waals force between DES and flavonoids, which would result in insignificant improvement of extraction yield. The $\mathrm{ChCl} / \mathrm{LA} 1$ containing $40 \%(\mathrm{w} / \mathrm{w})$ water produced higher extraction yield than that of $\mathrm{P} / \mathrm{LA} 1$ containing $40 \%(\mathrm{w} / \mathrm{w})$ water, which might be due to a better polarity match of $\mathrm{ChCl} / \mathrm{LA} 1$ containing $40 \%(\mathrm{w} / \mathrm{w})$ water with target Ginkgo flavonoid glycosides, and/or due to a more pronounced viscosity decrease of $\mathrm{ChCl} / \mathrm{LA} 1$ containing $40 \%(\mathrm{w} / \mathrm{w})$. Thus, $\mathrm{ChCl} / \mathrm{LA} 1$ containing $40 \%(\mathrm{w} / \mathrm{w})$ was selected for further study.

\section{Effect of the DES-water mixture to solid ratio}

A low ratio of solvent to solid may lead to an incomplete extraction, but a high ratio of solvent to solid can make the process complex and lead to DES waste. The effect of varied ratios between DES volumeand Ginkgo biloba leaves powder weight $(7.5: 1,10: 1,12.5: 1,15: 1,20: 1,30: 1$, and $50: 1)$ on the extraction yield of Ginkgo flavonoids was investigated. As shown in Fig. 3, the extraction yield of the target Ginkgo flavonoids increased a little with the increase in DES volume before DES-water mixture to solid ratio reached 10:1, and then the extraction yield remained almost unchanged with a further increase in DES volume. At DES-water mixture to solid ratio of 10:1, the Ginkgo biloba leaves powder and DES-water mixture might have mixed thoroughly. Hence, further increase in solvent to solid ratio could not lead to increase in extraction yield of Ginkgo flavonoids. Considering the DES consumption, DES-water mixture to solid ratio of 10:1 was used for the extraction of target flavonoids. 


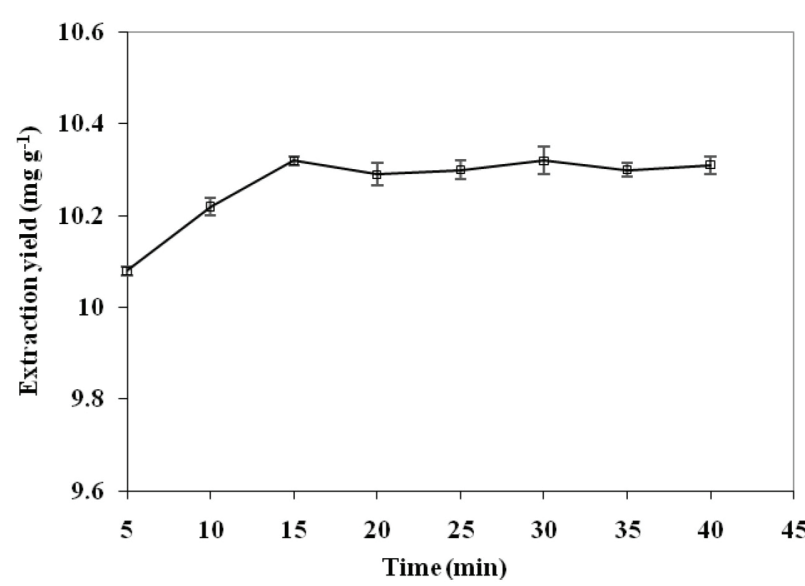

Fig. 4 - Effect of extraction time on the extraction yield of Ginkgo flavonoids. ChCl/LAl containing $40 \%(w / w)$ water was used as extraction solvent at a solvent to solid ratio of 1:10 with stirring at $50{ }^{\circ} \mathrm{C}$ and $150 \mathrm{rpm}$ for different times.

\section{Effect of extraction time}

The choice of an appropriate extraction time is important to ensure the extraction equilibrium of target Ginkgo flavonoids between Ginkgo biloba leaves powder and DES-water mixture. The extraction was carried out with different extraction times ranging from 5 to $40 \mathrm{~min}$. The results are shown in Fig. 4. The extraction yield of Ginkgo flavonoids increased slowly with the extension of extraction time within the first $15 \mathrm{~min}$. After $15 \mathrm{~min}$, the extraction time had little effect on the extraction yield, indicating that Ginkgo flavonoids reached their extraction equilibrium at around $15 \mathrm{~min}$. The extraction yield at $15 \mathrm{~min}$ was $10.32 \pm 0.01 \mathrm{mg} \mathrm{g}^{-1}$. The sample extracted for $15 \mathrm{~min}$ was centrifuged at $10000 \mathrm{rpm}$ for $10 \mathrm{~min}$, and the precipitate was re-extracted using the same method for another two times. The result showed that the extraction yield was about $0.013 \mathrm{mg} \mathrm{g}^{-1}$ in the second extraction, and could not be determined in the third extraction, which indicated that $99.87 \%$ of extractable Ginkgo flavonoids had been extracted from the Ginkgo biloba leaves powder in the first step. Considering the increase in extraction yield and the shorter extraction time, 15 min was selected as the proper extraction time.

Compared with the traditional extraction solvents, the DES-based method for extraction of Ginkgo flavonoids showed advantages of greenness, and exhibiting high-efficiency and environmental friendliness ${ }^{8-11}$. A ternary deep eutectic solvent made from choline chloride, oxalic acid and ethylene glycol had also been prepared to extract flavonoids from Ginkgo biloba leaves ${ }^{33}$. In that work, the optimized extraction temperature and time were $60{ }^{\circ} \mathrm{C}$ and $30 \mathrm{~min}$, respectively. Comparatively speaking, the $\mathrm{DES}(\mathrm{ChCl} / \mathrm{LA} 1)$ developed in this work was more efficient and energy saving.

\section{Recovery of Ginkgo flavonoids from the DES extraction solution}

The recovery of target compounds from DES extraction solution is a challenging task due to the negligible vapor pressure and the generally high water miscibility of $\mathrm{DESs}^{25,28}$. Several approaches have been suggested to recover the target compounds, including the application of antisolvents, recrystallization, back extraction, chromatographic techniques, and countercurrent separation ${ }^{13,34}$. In this work, the recovery of the target Ginkgo flavonoids from DES extraction solution was attempted using six macroporous resins. The results showed that all the six macroporous resins could adsorb the Ginkgo flavonoids with different adsorption yield. The adsorption yields for HPD450, HPD417, DM130 and ADS-17 were all lower than $60 \%$. The adsorption yield for D101 reached $85.2 \%$. The AB-8 resin gave the maximum adsorption yield of $93.7 \%$. The AB-8 resin adsorbing Ginkgo flavonoids washed twice with $95 \%$ (v/v) ethanol solution could free almost all the Ginkgo flavonoids to the ethanol solution. Therefore, the AB- 8 resin was effective for recovering the target Ginkgo flavonoids.

\section{Conclusion}

This work has demonstrated that $\mathrm{ChCl} / \mathrm{LA} 1$ containing $40 \%(\mathrm{w} / \mathrm{w})$ water can be used as an alternative solvent to efficiently extract Ginkgo flavonoids from Ginkgo biloba leaves. This DES-based method gives a very high extraction efficiency of $99.87 \%$ in only 15 min. The Ginkgo flavonoids in the DES extraction solution can also be easily recovered by the AB- 8 macroporous resin.

\section{ACKNOWLEDGEMENTS}

This work was supported by the "China Postdoctoral Science Foundation (2016M600417 and 2017T100373)", the "333 project of Jiangsu Province (BRA2017458)", the "Six Talent Peaks Project in Jiangsu Province (2015-JY-016)", the "Open Project of State Key Laboratory of Natural Medicines (No. SKLNMKF201802)", and "A Project Funded by the Priority Academic Program Development of Jiangsu Higher Education Institutions, PAPD”. 


\section{Abbreviations}

DESs - - Deep eutectic solvents

HPLC - High performance liquid chromatography

SFE - Supercritical $\mathrm{CO}_{2}$ extraction technology

HBDs - Hydrogen bond donors

HBAs - Hydrogen bond acceptors

UAE - Ultrasound-assisted extraction

HPD450, - Different macroporous resins

HPD417,

DM130,

ADS-17,

AB-8, D101

\section{References}

1. Chen, P., Ozcan, M., Harnly, J., Chromatographic fingerprint analysis for evaluation of Ginkgo biloba products, Anal. Bioanal. Chem. 389 (2007) 251. doi: https://doi.org/10.1007/s00216-007-1386-9

2. Maurer, K., Ihl, R., Dierks, T., Frölich, L., Clinical efficacy of Ginkgo biloba special extract EGb 761 in dementia of the Alzheimer type, J. Psychiatr. Res. 31 (1997) 645. doi: https://doi.org/10.1016/S0022-3956(97)00022-8

3. Oyama, Y., Chikahisa, L., Ueha, T., Kanemaru, K., Noda, $K$., Ginkgo biloba extract protects brain neurons against oxidative stress induced by hydrogen peroxide, Brain. Res.712 (1996) 349. doi: https://doi.org/10.1016/0006-8993(95)01440-3

4. Van Beek, T. A., Chemical analysis of Ginkgo biloba leaves and extracts, J. Chromatogr. A. 967 (2002) 21. doi: https://doi.org/10.1016/S0021-9673(02)00172-3

5. Van Beek, T. A., Montoro, P., Chemical analysis and quality control of Ginkgo biloba leaves, extracts, and phytopharmaceuticals, J. Chromatogr. A. 1216 (2009) 2002. doi: https://doi.org/10.1016/j.chroma.2009.01.013

6. Chan, P. C., Xia, Q., Fu, P. P., Ginkgo biloba leaf extract: Biological, medicinal, and toxicological effects, Environ. Carcinog. Ecotoxicol. Rev. 25 (2007) 211. doi: https://doi.org/10.1080/10590500701569414

7. Li. J., Chase, H. A., Use of expanded bed adsorption to purify flavonoids from Ginkgo biloba L., J. Chromatogr. A. 1216 (2009) 8759. doi: https://doi.org/10.1016/j.chroma.2009.03.002

8. Wang, J. H., Cao, F. L., Su, E. Z., Wu, C. E., Zhao, L. G., Ying, $R$. F., Improving flavonoid extraction from Ginkgo biloba leaves by prefermentation processing, J. Agric. Food Chem. 61 (2013) 5783. doi: https://doi.org/10.1021/jf400712n

9. Yang, C., Xu, Y. R., Yao, W. X., Extraction of pharmaceutical components from Ginkgo biloba leaves using supercritical carbon dioxide, J. Agric. Food Chem. 50 (2002) 846. doi: https://doi.org/10.1021/jf010945f

10. Chiu, K. L., Cheng, Y. C., Chen, J. H., Chang, C. J., Yang, $P$. $W$., Supercritical fluids extraction of Ginkgo ginkgolides and flavonoids, J. Supercrit. Fluids. 24 (2002) 77. doi: https://doi.org/10.1016/S0896-8446(02)00014-1

11. Miao, S. F., Yu, J. P., Du, Z., Guan, Y. X., Yao, S. J., Zhu, Z. Q., Supercritical fluid extraction and micronization of Ginkgo flavonoids from Ginkgo Biloba leaves, Ind. Eng. Chem. Res. 49 (2010) 5461. doi: https://doi.org/10.1021/ie902001x
12. Tang, B. K., Zhang, H., Row, K. H., Application of deep eutectic solvents in the extraction and separation of target compounds from various samples, J. Sep. Sci. 38 (2015) 1053 . doi: https://doi.org/10.1002/jssc.201401347

13. Dai, Y. T., Spronsen, J. V., Witkamp, G. J., Verpoorte, R., Choi, Y. H., Ionic liquids and deep eutectic solvents in natural products research: Mixtures of solids as extraction solvents, J. Nat. Prod. 76 (2013) 2162. doi: https://doi.org/10.1021/np400051w

14. Abbott, A. P., Capper, G., Davies, D. L., Rasheed, R. K., Tambyrajah, $V$., Novel solvent properties of choline chloride/urea mixtures, Chem. Commun. 1 (2003) 70. doi: https://doi.org/10.1039/b210714g

15. Tang, B. K., Row, K. H., Recent developments in deep eutectic solvents in chemical sciences, Monatsh. Chem. 144 (2013)1427. doi: https://doi.org/10.1007/s00706-013-1050-3

16. Zhang. Q., Vigier, K. D. O., Royer, S., Jérôme, F., Deep eutectic solvents: Syntheses, properties and applications, Chem. Soc. Rev. 41 (2012) 7108. doi: https://doi.org/10.1039/c2cs35178a

17. Francisco, M., Bruinhorst, A. V. D., Kroon, M. C., Low-Transition-Temperature Mixtures (LTTMs): A new generation of designer solvents, Angew. Chem. Int. Ed. 52 (2013) 3074. doi: https://doi.org/10.1002/anie.201207548

18. Li. J., Han, Z. J., Zou, Y. P., Yu, B., Efficient extraction of major catechins in Camellia sinensis leaves using green choline chloride-based deep eutectic solvents, RSC Adv. 5 (2015) 93937. doi: https://doi.org/10.1039/C5RA15830C

19. Ruß. C., König. B., Low melting mixtures in organic synthesis - an alternative to ionic liquids? Green Chem. 14 (2012) 2969. doi: https://doi.org/10.1039/c2gc36005e

20. Zeng, Q., Wang, Y., Huang, Y., Ding, X., Chen, J., Xu, K., Deep eutectic solvents as novel extraction media for protein partitioning, Analyst. 139 (2014) 2565. doi: https://doi.org/10.1039/c3an02235h

21. Dai, Y. T., Witkamp, G. J., Verpoorte, R., Choi, Y. H., Natural deep eutectic solvents as a new extraction media for phenolic metabolites in Carthamus tinctorius L., Anal. Chem. 85 (2013) 6272. doi: https://doi.org/10.1021/ac400432p

22. Gu, T. N., Zhang, M. L., Tan, T., Chen, J., Li, Z., Zhang, Q. H., Qiu, H. D., Deep eutectic solvents as novel extraction media for phenolic compounds from model oil, Chem. Commun. 50 (2014) 11749. doi: https://doi.org/10.1039/C4CC04661G

23. Jeong, K. M., Zhao, J., Jin, Y., Heo, S. R., Han, S. Y., Yoo, $D$. E., Lee, J., Highly efficient extraction of anthocyanins from grape skin using deep eutectic solvents as green and tunable media, Arch. Pharm. Res. 38 (2015) 2143. doi: https://doi.org/10.1007/s12272-015-0678-4

24. Zhang, H., Tang, B. K., Row, K. H., A green deep eutectic solvent-based ultrasound-assisted method to extract astaxanthin from shrimp byproducts, Anal. Lett. 47 (2014) 742. doi: https://doi.org/10.1080/00032719.2013.855783

25. Jeong, K. M., Lee, M. S., Nam, M. W., Zhao, J., Jin, Y., Lee, D. K., Kwon, S. W., Jeong, J. H., Lee, J., Tailoring and recycling of deep eutectic solvents as sustainable andefficient extraction media, J. Chromatogr. A. 1424 (2015)10. doi: https://doi.org/10.1016/j.chroma.2015.10.083 
26. Qi, X. L., Peng, X., Huang, Y. Y., Li, L., Wei, Z. F., Zu, Y. G., $F u$, Y. J., Green and efficient extraction of bioactive flavonoids from Equisetum palustre L. by deep eutectic solvents-based negative pressure cavitation method combined with macroporous resin enrichment, Ind. Crop. Prod. 70 (2015) 142 .

doi: https://doi.org/10.1016/j.indcrop.2015.03.026

27. Bi, W. T., Tian, M. L., Row, K. H., Evaluation of alcohol-based deep eutectic solvent in extraction and determination of flavonoids with response surface methodology optimization, J. Chromatogr. A. 1285 (2013) 22.

doi: https://doi.org/10.1016/j.chroma.2013.02.041

28. Nam, M. W., Zhao, J., Lee, M. S., Jeong, J. H., Lee, J., Enhanced extraction of bioactive natural products using tailor-made deep eutectic solvents: Application to flavonoid extraction from Flossophorae, Green Chem. 17 (2015) 1718.

doi: https://doi.org/10.1039/C4GC01556H

29. Wei, Z. F., Wang, X. Q., Peng, X., Wang, W., Zhao, C. J., Zu, $Y$. G., $F u, Y$. J., Fast and green extraction and separation of main bioactive flavonoids from Radix Scutellariae, Ind. Crop Prod. 63 (2015) 175 doi: https://doi.org/10.1016/j.indcrop.2014.10.013

30. Abbott, A. P., Boothby, D., Capper, G., Davies, D. L., Rasheed, $R$. K., Deep eutectic solvents formed between choline chloride and carboxylic acids: Versatile alternatives to ionic liquids, J. Am. Chem. Soc. 126 (2004) 9142.

doi: https://doi.org/10.1021/ja048266j

31. Hasler, A., Sticher, Q., Meier, B., Identification and determination of the flavonoids from Ginkgo biloba by high performance liquid chromatography, J. Chromatogr. A. 605 (1992) 41 doi: https://doi.org/10.1016/0021-9673(92)85026-P

32. Lu, C., Cao, J., Wang, N., Su, E. Z., Significantly improving the solubility of nonsteroidal anti-inflammatory drugs in deep eutectic solvents for potential non-aqueous liquid administration, Med. Chem. Commun. 7 (2016) 955. doi: https://doi.org/10.1039/C5MD00551E

33. Tang, W., Li, G., Chen, B., Zhu, T., Row, K. H., Evaluating ternary deep eutectic solvents as novel media for extraction of flavonoids from Ginkgo biloba, Sep. Sci. Technol. 52 (2017) 91 doi: https://doi.org/10.1080/01496395.2016.1247864

34. Liu, Y., Garzon, J., Friesen, J. B., Zhang, Y., McAlpine, J. B., Lankin, D. C., Chen, S. N., Pauli, G. F., Countercurrent assisted quantitative recovery of metabolites from plant-associated natural deep eutectic solvents, Fitoterapia. 112 (2016) 30 . doi: https://doi.org/10.1016/j.fitote.2016.04.019 